\title{
Hiperplasia embrionária epitelial da cápsula de Bowman pós-diálise crônica simulando nefroblastomatose: relato de caso
}

\author{
Embryonal hiperplasia of Bowman's capsule epithelium after dialysis simulating nephroblastomatosis: \\ case report
}

\author{
Lúcia de Noronha ${ }^{1}$ \\ Maria Betânia Beppler² \\ Cynthia Melissa Valério ${ }^{2}$ \\ Carla Martinez Menini² \\ Maria José Serapião ${ }^{3}$ \\ Elizabeth Schneider Gugelmin ${ }^{4}$
}

\begin{tabular}{l|l}
\multicolumn{1}{c|}{ unitermos } & resumo \\
Hiperplasia embrionária & $\begin{array}{l}\text { A hiperplasia embrionária epitelial da cápsula de Bowman (HEECB) é uma rara alteração pós- } \\
\text { Cápsula de Bowman }\end{array}$ \\
Diálise & $\begin{array}{l}\text { Destaca-se a sua importância por simular histologicamente a nefroblastomatose universal, } \\
\text { uma entidade pré-neoplásica precursora do tumor de Wilms. Neste artigo, relatamos o caso } \\
\text { incomum de um paciente de } 12 \text { anos de idade, cujos rins, após } 32 \text { meses de terapia dialítica, } \\
\text { apresentaram alterações compatíveis com HEECB. }\end{array}$
\end{tabular}

\section{abstract}

Embryonal hiperplasia of Bowman's capsule epithelium is a rare after dialysis alteration of kidneys in final phase of evolution, which has few descriptions in the medical literature. It stands out its importance for simulating histologically the universal nephroblastomatosis, a precursor entity of the Wilms' tumor. In this article, we report a 12 year-old patient's unusual case undergoing dialysis during thirty-two months, whose kidneys presented features consisted with embryonal hiperplasia of Bowman's capsule epithelium. key words

Embryonal hiperplasia

Bowman's capsule

Dialysis

\section{Introdução}

A hiperplasia embrionária epitelial da cápsula de Bowman (HEECB) é caracterizada pela associação de glomérulos esclerosados com células embrionárias indiferenciadas, que se dispõem na forma de nódulos localizados na parte parietal da cápsula de Bowman. Esta lesão ocorre somente no córtex renal, o que a diferencia da nefroblastomatose universal (4).

A HEECB é uma alteração rara que constitui um dos difíceis diagnósticos diferenciais de nefroblastomatose e, uma vez que a nefroblastomatose é uma entidade pré-neoplásica precursora do tumor de
Wilms, faz-se importante o esclarecimento acerca de todos os seus diagnósticos diferenciais, mesmo os raros, como neste caso. Afinal, o caráter não-neoplásico da doença é fator determinante tanto de seu tratamento quanto de seu prognóstico $(1,4)$.

A HEECB é uma entidade com poucas descrições na literatura médica mundial. Os poucos relatos existentes referem-se a achados de necropsia ou de rins removidos para transplante. O presente estudo objetiva relatar o caso de um paciente com HEECB pós-diálise simulando nefroblastomatose universal (7).
1. Professora assistente da Pontifícia Universidade Católica do Paraná (PUC/PR); Laboratório de Patologia Experimental (LPE) da PUC/PR; mestre em Patologia.

2. Acadêmica da PUC/PR; estagiária do LPE da PUC/PR.

3. Professora adjunta da Universidade Federal do Paraná.

4. Patologista do Hospital Infantil Pequeno Príncipe, Curitiba-PR. 


\section{Relato do caso}

Paciente GVS, masculino, 13 anos, nascido de cesariana, pesando $3.490 \mathrm{~g}$, nega história familiar de hipertensão arterial sistêmica ou nefropatias.

Aos 3 anos de idade começou a apresentar um quadro de síndrome nefrótica corticorresistente, devidamente tratado por dois anos, evoluindo desfavoravelmente. Dois anos depois, o paciente foi submetido a biopsia renal por insuficiência renal crônica (IRC), que revelou glomeruloesclerose focal e segmentar incipiente com atrofia tubular leve e nefrite intersticial aguda.

Com a evolução para o quadro de IRC, o paciente, aos 8 anos de idade, foi submetido a terapia dialítica peritoneal por dez meses, com conseqüentes quadros de peritonite de repetição por infecção. A partir dos 9 anos, o paciente passou a ser submetido a três sessões de hemodiálise por semana, durante as quais o tratamento prosseguiu com poucas intercorrências.

Aos 11 anos, o paciente foi submetido a nefrectomia bilateral, cujo laudo anatomopatológico revelou rins com características macroscópicas de esclerose. $\mathrm{O}$ rim direito pesou $95 \mathrm{~g}$ e o esquerdo, $88 \mathrm{~g}$; a cápsula era aderida à superfície renal e espessada. A superfície renal era rugosa e fosca, com algumas cicatrizes rasas e pequenas. Aos cortes, a cortical media $0,6 \mathrm{~cm}$ em espessura com áreas de fibrose, e a medula era levemente congesta. A microscopia revelou extensa glomeruloesclerose com atrofia tubular e inflamação e fibrose intersticial. Havia moderado espessamento da camada média das artérias de médio calibre, compatível com alterações renais de fase terminal (Figuras 1 e 2). Porém os rins também apresentaram inúmeros focos de proliferação de células pequenas e imaturas, com núcleos hipercromáticos, nucléolos inconspícuos e citoplasma inaparente, formando agregados sólidos ou cordões. A proliferação era encontrada predominantemente junto à cápsula de Bowman. Estes achados são compatíveis com o diagnóstico de HEECB (Figuras 2 e 3).

Atualmente, o paciente continua a terapia dialítica e mantém quadro clínico estável e sem intercorrências.

\section{Discussão}

Pacientes portadores de doenças que cursam com IRC encontram na terapia dialítica um procedimento eficiente, porém deletério, no prolongamento de sua sobrevida. As principais alterações do tecido renal clinicamente re-

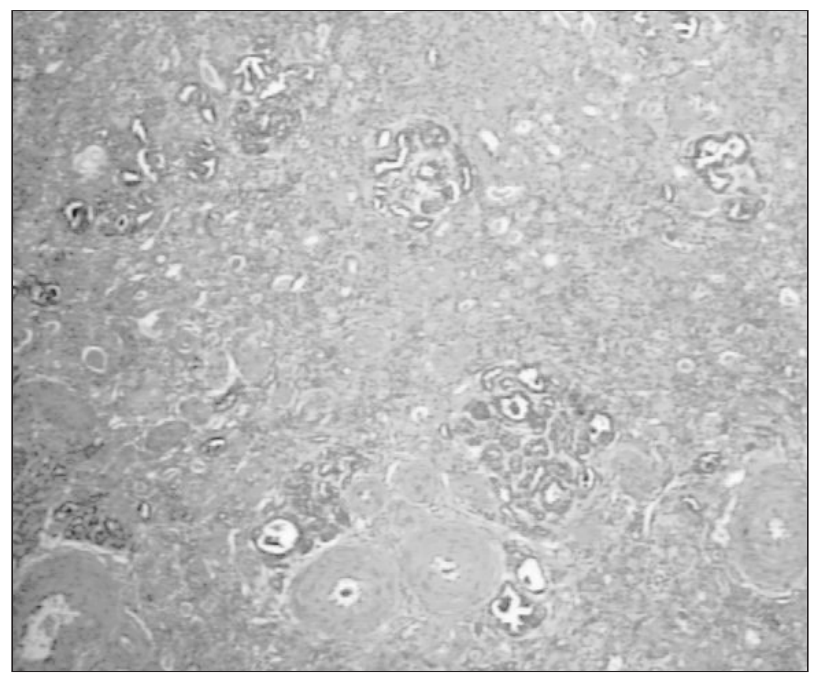

Figura 1 - Corte histológico corado em hematoxilina-eosina apresentando tecido renal com glomérulos esclerosados e focos de atrofia tubular, além de infiltrado inflamatório mononuclear intersticial. Presença de múltiplos focos de proliferação epitelial de células pequenas próximo aos glomérulos (HE 40X)

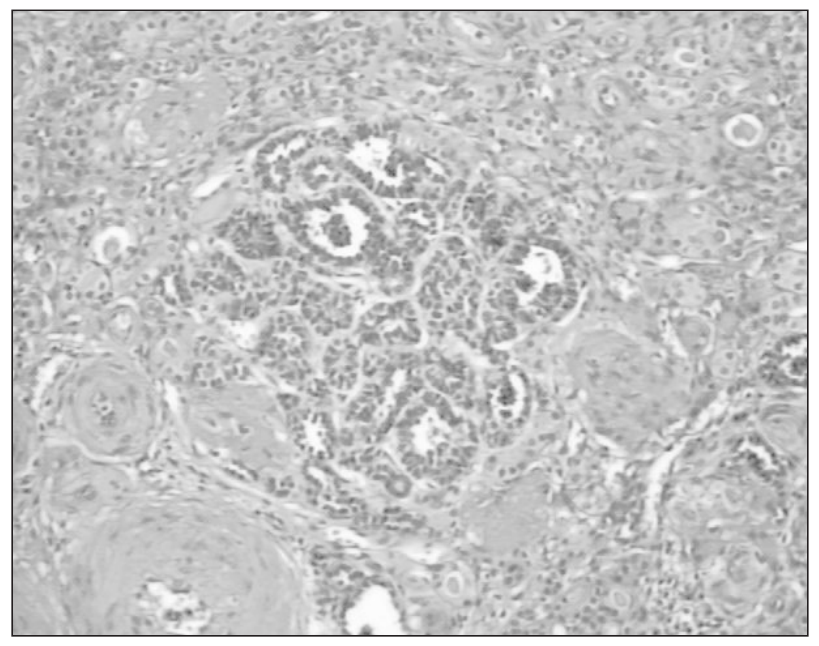

Figura 2 - Proliferação de células pequenas indiferenciadas formando um padrão pseudocribriforme localizada na cápsula de Bowman (HE 100x)

levantes causadas pela cronicidade da diálise são achado ocasional de quando os pacientes são investigados radiologicamente, ou de quando os rins são examinados após nefrectomia uni ou bilateral ou necropsias. Sua apresentação mais comum se faz sob a forma de doenças císticas adquiridas, descritas pela primeira vez por Dunnil et al. (2).

Os cistos da doença cística adquirida associada à diálise são constituídos por uma membrana de epitélio cubóide ou pavimentoso cubóide, semelhantes aos cistos simples encontrados em pacientes com achados ocasionais. Clinicamente, sangramentos no interior dos cistos podem cursar com hematúria em pacientes 


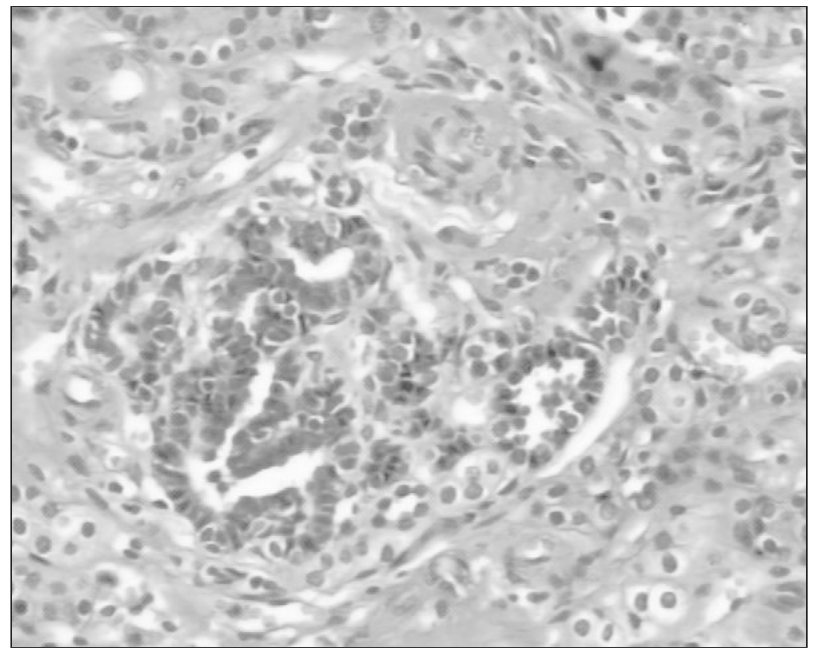

Figura 3 - Proliferação de células de aspecto blastematoso, com citoplasma escasso e núcleos hipercromáticos (HE 400x)

previamente oligúricos. A causa da transformação cística não é conhecida, mas possivelmente é resultado da hiperplasia em grupos de néfrons não completamente destruídos pela doença (2).

Alguns cistos podem ser classificados como cistos atípicos quando possuem alterações hiperplásicas no seu epitélio de revestimento. Estes cistos atípicos estão presentes em um terço dos rins em fase terminal devido à diálise. Quando o grau de hiperplasia é muito acentuado, os cistos tornam-se papilíferos, e aqui se faz presente a importância da distinção com adenomas papilíferos (3). A transformação cística do rim e a tendência ao desenvolvimento de neoplasia são fenômenos próximos, porém não absolutamente relacionados nos pacientes com IRC. Alterações císticas nos rins tendem a estar associadas com diferentes graus de hiperplasia e com uma maior chance de incidência de neoplasia. Destacam-se, neste caso, os adenomas e carcinomas de células renais em pacientes mais jovens, com IRC e submetidos previamente a diálise $(3,6)$.

Em 1978, Hughson fez a primeira descrição de HEECB em 40 pacientes que apresentavam cistos atípicos (4). Em seu estudo, quatro dos 40 pacientes submetidos a diálise num período de dois a 24 meses apresentavam alterações típicas de HEECB. As células arredondadas, cubóides, formando tufos de aparência embrionária na córtex da cápsula de Bowman, tinham seu núcleo bem corado por hematoxilina, e o citoplasma, por Luxol fast blue e tricrômico de Gomori. Hughson acreditava que os nódulos celulares possuíam provável origem muscular.
Ogata, em 1991, relatou 18 casos de HEECB entre 58 rins estudados, com tempo de diálise variando de 12 a 20 meses (7). No presente caso, o paciente foi submetido a diálise por 32 meses, prolongado tempo de manutenção do parênquima renal se comparado com a literatura.

Entre as lesões que poderiam ser consideradas no diagnóstico diferencial da HEECB, do ponto de vista anatomopatológico, destaca-se a nefroblastomatose: lesão pré-neoplásica de etiologia genética e não-relacionada à diálise; caracterizada pela presença de focos de células nefrogênicas, múltiplos e difusos, cursando com nefromegalia bilateral maciça, porém com a forma original do órgão preservada. O parênquima encontra-se difusa e multifocalmente substituído por células nefrogênicas embrionárias, com aparência semelhante à do componente blastematoso do tumor de Wilms e à das células vistas na HEECB. Esta descrição foi documentada pela primeira vez por Hou e Holman (5) e corresponde ao tipo universal ou panlobular de nefroblastomatose, uma vez que acomete, de forma difusa, todo o parênquima renal. Beckwith et al. (1) citaram a HEECB como diagnóstico diferencial de ninhos nefrogênicos panlobulares e de tumor de Wilms, salientando a raridade do diagnóstico.

$\mathrm{Na}$ HEECB, os focos de células embrionárias nefrogênicas estão restritos somente à camada cortical do rim, com localização na porção interna da cápsula de Bowman. A semelhança destes focos de células embrionárias com o tecido embrionário renal visto nas nefroblastomatoses é marcada pela aparência de "desdiferenciada" das primeiras (4), assim como esta aparência as torna semelhantes ao componente blastematoso do tumor de Wilms.

Sabe-se que é possível formar células totalmente indiferenciadas em tecidos completamente maduros, visando a organogênese. Isto ocorre devido à proliferação de células-tronco ou à reversão de propriedades citofisiológicas previamente adquiridas com o processo de diferenciação celular. Isto pode ser uma explicação fisiopatológica para o fenômeno conhecido como HEECB (1).

A HEECB é um elemento estrutural importante nos rins consideravelmente alterados de pacientes em estágio final de falência renal submetidos a diálise, e sua importância repousa em sua raridade e semelhança com lesões préneoplásicas e neoplásicas (1). 


\section{Referências}

I. Beckwith, J.B.; Kiviat, N.B. \& Bonadio, J.F. Nephrogenic rests, nephroblastomatosis and the pathogenesis of Wilms' tumor. Pediatr. Pathol., 10( I-2): I-36, 1990.

2. Dunnil, M.S.; Millard, P.R. \& Oliver, D. Acquired cystic disease of the kidneys: a hazard of long-term intermittent maintenance hemodialysis. J. Clin. Pathol., 30: 868-77, 1977.

3. Hughson, M.D.; Buchwald, D. \& Fox, M. Renal neoplasia and acquired cystic kidney disease in patients receiving long-term dialysis. Arch. Pathol. Lab. Med., I l 0:592-600, 1986.
4. Hughson, M.S.; McManus, J.F.A. \& Hennigar, G.R. Embryonal hiperplasia of Bowman's capsular epithelium. Am. J. Pathol., 91:71-80, 1978.

5. Hou, L.T. \& Holman, R.L. Bilateral nephroblastomatosis in a premature infant. J. Pathol. Bacteriol., 82: 249-55, 1961.

6. Ishikawa, I. \& Shinoda, A. Renal adenocarcinoma with acquired cysts in chronic hemodialysis patients. Clin. Nephrol., 20:32 I-2, 1983.

7. Ogata, K. Clinicopathological study of kidneys from patients on chronic dialysis. Kidney Int., 37(5): 1333-40, 1990. 